\title{
Indications for, Timing of, and Modes of Delivery in a National Cohort of Women Admitted With Antepartum Hemorrhage at $22+0$ to $28+6$ Weeks' Gestation
}

\author{
Jeanelle N. Sabourin, MD, FRCSC, ${ }^{1}$ Tang Lee, MSc, ${ }^{2}$ Laura A. Magee, MD, FRCPC, ${ }^{2,3}$ \\ Peter von Dadelszen, MBChB, DPhil, FRCSC, ${ }^{2}$ Nestor Demianczuk, MD, FRCSC'; \\ for the Canadian Perinatal Network Collaborative Group
}

${ }^{1}$ Department of Obstetrics and Gynecology, University of Alberta, Edmonton AB

${ }^{2}$ Department of Obstetrics and Gynaecology, University of British Columbia, Vancouver BC

${ }^{3}$ Department of Medicine, University of British Columbia, Vancouver BC

This paper was presented at the ACOG Districts VIII \& IX 2011 Annual District Meeting in Los Cabos, Baja California Sur, Mexico, October 30th, 2011.

\section{Abstract}

Objective: Antepartum hemorrhage is associated with preterm birth and operative delivery. Since the Canadian Perinatal Network records obstetric interventions for women admitted to tertiary care hospitals with antepartum hemorrhage, our objective was to describe the delivery characteristics of this cohort.

Methods: Trained abstractors collected data by chart review from women admitted with antepartum hemorrhage between $22+0$ and $28+6$ weeks' gestation. We included all women with complete follow-up postpartum and used descriptive statistics to report the indications for, timing of, and modes of delivery.

Results: The study cohort included 806 women from 13 tertiary perinatal centres in six provinces. The most common causes of bleeding were placental abruption $(n=256)$ and placenta previa $(n=171)$. The median gestational age at delivery was 30 weeks, and $497(61.7 \%)$ births occurred at less than 34 weeks. Over one half of the women began labour spontaneously, and 238 (29.5\%) were delivered prior to the onset of labour. Overall, 370 (45.9\%) women delivered vaginally, including 98 who had induction of labour. Of the 436 Caesarean sections (54.1\%), 345 (79.1\%) were emergencies. The most common indications for Caesarean section were placenta previa, abnormal fetal presentation, and placental abruption or vaginal bleeding.

Key Words: Antepartum hemorrhage, indication for delivery, premature birth, high-risk pregnancy, mode of delivery

Competing Interests: None declared.

Received on February 16, 2012

Accepted on June 21, 2012
Conclusion: This inpatient cohort of women with antepartum hemorrhage had high rates of spontaneous labour, preterm birth, and emergency Caesarean section. These results can be used as current Canadian benchmark rates of preterm delivery, induction of labour, and Caesarean section in women admitted to tertiary care centres with antepartum hemorrhage between $22+0$ and $28+6$ weeks' gestation, and can aid in the counselling of similar women.

\section{Résumé}

Objectif : L'hémorragie antepartum est associée à l'accouchement préterme et opératoire. Puisque le Réseau périnatal canadien consigne les interventions obstétricales menées chez les femmes admises dans les hôpitaux de soins tertiaires en raison d'une hémorragie antepartum, notre objectif était de décrire les caractéristiques de l'accouchement au sein de cette cohorte.

Méthodes : Des résumeurs formés ont recueilli des données au moyen de l'analyse des dossiers des femmes hospitalisées en raison d'une hémorragie antepartum entre $22+0$ et $28+6$ semaines de gestation. Nous avons inclus toutes les femmes comptant un suivi postpartum exhaustif et nous avons fait appel à la statistique descriptive pour signaler les paramètres suivants en ce qui a trait à l'accouchement : indications, chronologie et modes utilisés.

Résultats : La cohorte d'étude comptait 806 femmes en provenance de 13 centres périnataux tertiaires dans six provinces. Les causes les plus courantes de l'hémorragie étaient le décollement placentaire $(n=256)$ et le placenta prævia $(n=171)$. L'âge gestationnel médian au moment de l'accouchement était de 30 semaines et 497 accouchements $(61,7 \%)$ ont eu lieu à moins de 34 semaines. Plus de la moitié des femmes ont connu un travail spontané et 238 femmes $(29,5 \%)$ ont accouché avant le début du travail. En tout, 370 femmes (45,9\%) ont connu un accouchement vaginal, dont 98 qui ont subi un déclenchement du travail. Parmi les 436 césariennes menées (54,1\%), 345 
$(79,1 \%)$ étaient des urgences. Les indications les plus courantes de césarienne étaient le placenta prævia, la présentation fœtale anormale et le décollement placentaire ou le saignement vaginal.

Conclusion : Cette cohorte de femmes hospitalisées en raison d'une hémorragie antepartum présentait des taux élevés de travail spontané, d'accouchement préterme et de césarienne d'urgence. Ces résultats peuvent être utilisés à titre de taux de référence canadiens actuels en ce qui a trait à l'accouchement préterme, au déclenchement du travail et à la césarienne chez les femmes admises en centre de soins tertiaires, entre $22+0$ et $28+6$ semaines de gestation, en raison d'une hémorragie antepartum, ainsi que contribuer au counseling des femmes se trouvant dans des situations semblables.

J Obstet Gynaecol Can 2012;34(11):1043-1052

\section{INTRODUCTION}

$\mathrm{V}$ aginal bleeding during pregnancy is common, with self-reported and documented rates of $16 \%$ to $26 \%{ }^{1-7}$ Such bleeding typically occurs in early pregnancy, and the majority of reports have studied first trimester bleeding. ${ }^{1-7}$ On the other hand, antepartum hemorrhage is defined as bleeding in late pregnancy, usually occurring after 20 weeks' gestation and unassociated with labour and delivery. The causes of APH are mostly bleeding from placental abruption and placenta previa, less commonly from causes such as vasa previa or uterine rupture, and in the remainder of cases unknown. ${ }^{8}$

Antepartum hemorrhage can result in antepartum hospital admission in over one quarter of women with bleeding in the second trimester. ${ }^{1}$ Increased risks for infants born to women with vaginal bleeding in pregnancy include preterm delivery, growth restriction and low birth weight, congenital malformations, and stillbirth and perinatal mortality., $, 5,7,9-14$ Although maternal mortality is rare, morbidity may include hemorrhage and a need for blood transfusion, surgery, hospitalization, or intensive care. ${ }^{10,12,15,16}$ Despite this, maternal outcomes are infrequently reported.

The Canadian Perinatal Network maintains a database of information collected from a prospective cohort of women at high risk for preterm birth; these women are admitted to participating centres across the country with one or more "indicator" conditions that include antepartum hemorrhage. The CPN provides representative national rates and frequencies of obstetrical and neonatal interventions and outcomes for these women and their babies. ${ }^{17}$

\section{ABBREVIATIONS}

$\mathrm{APH}$ antepartum hemorrhage

CPN Canadian Perinatal Network

NOS not otherwise specified
The overall objective of the CPN is to improve the quality of perinatal care by examining variations in obstetrical and neonatal practice and outcomes and by identifying the best management strategies. ${ }^{17}$ The objective of our study was to use the $\mathrm{CPN}$ database to determine the indications for, timing of, and modes of delivery in this national cohort of women admitted to hospital with APH. These baseline statistics and frequencies will establish current Canadian rates of preterm delivery, induction of labour, and Caesarean section in this high-risk group that can be used for future comparisons and to aid in counselling similar women.

\section{METHODS}

The CPN comprises 23 Canadian tertiary perinatal units and has collected data since August 2005. ${ }^{17}$ Research ethics committees at each participating centre reviewed and approved the $\mathrm{CPN}$ as a quality assurance project not requiring individual informed consent. Experience with this process has been detailed elsewhere. ${ }^{18}$ This project was explicitly outlined in the CPN ethics applications for each site.

Women were eligible for entry into the database if they were admitted at between $22+0$ and $28+6$ weeks' gestation to a participating unit with one or more of the predefined indicator conditions at admission (which include APH). In the CPN, $\mathrm{APH}$ is defined as greater than $15 \mathrm{~mL}$ of vaginal bleeding prior to the onset of labour, considered to be equivalent to a blood spot of approximately $2.5 \mathrm{~cm}$ in diameter. The bleeding does not have to occur in a single episode.

The details of the data collection process for the CPN have been previously documented. ${ }^{19}$ A trained data abstractor at each centre identified all potentially eligible women from delivery suite and antenatal ward logbooks, or from Canadian Institute for Health Information coded data searches. Maternal records were reviewed and included according to the CPN Working Protocol and Database Manual. Information collected focused on maternal outcomes, use of obstetric resources, patient mix, and obstetric care practices. To ensure reliability of data entry, data were re-abstracted from the source records for a random $5 \%$ of women. This process has shown a high level of agreement with the medical records at the largest CPN site. Information was collected by review of the maternal records from the time of hospital admission at eligibility until final discharge from hospital after delivery (including any related readmissions). Data were entered into standardized electronic collection forms and uploaded to the CPN through a secure hospital network.

For this analysis, we searched the database in April 2011. In total, 3619 women had been entered into the CPN from 13 


\begin{tabular}{|c|c|}
\hline \multicolumn{2}{|l|}{ CPN sites included in current APH cohort analysis } \\
\hline Victoria General Hospital & Victoria BC \\
\hline BC Women's Hospital \& Health Centre & Vancouver BC \\
\hline Foothills Medical Centre & Calgary $A B$ \\
\hline Royal Alexandra Hospital & Edmonton $\mathrm{AB}$ \\
\hline Royal University Hospital & Saskatoon SK \\
\hline Regina General Hospital & Regina SK \\
\hline Kingston General Hospital & Kingston ON \\
\hline Mount Sinai Hospital & Toronto ON \\
\hline The Ottawa Hospital & Ottawa ON \\
\hline Centre Hôspitalier Universitaire de Sherbrooke & Sherbrooke QC \\
\hline Centre Hôspitalier de L'Université Laval & Ste-Foy QC \\
\hline Hôpital Sainte-Justine & Montréal QC \\
\hline Women's Health Program, Eastern Health & St. John's NL \\
\hline \multicolumn{2}{|l|}{ Other CPN Sites* } \\
\hline Royal Columbian Hospital & New Westminster BC \\
\hline St. Boniface General Hospital & Winnipeg MB \\
\hline The Women's Hospital & Winnipeg MB \\
\hline McMaster University Medical Centre & Hamilton ON \\
\hline Saint Joseph's Health Centre & London ON \\
\hline Women's College Hospital & Toronto ON \\
\hline Royal Victoria Hospital & Montréal QC \\
\hline Saint John Regional Hospital & Saint John NB \\
\hline River Valley Hospital & Fredericton NB \\
\hline IWK Health Centre & Halifax NS \\
\hline
\end{tabular}

tertiary perinatal centres in six provinces that had already submitted information into the database (Table 1). No data were available from the other CPN sites for the analysis. We included all cases of women admitted with APH and followed to delivery. Causes of bleeding were identified in the patient's chart, in written records, or in ultrasound or pathology reports. Imaging was not required for the diagnosis of placental abruption. When abstractors did not identify a cause of APH from the record, the code "not otherwise specified" was used. More than one cause of bleeding or reason for induction of labour and Caesarean section could be recorded.

Descriptive statistics were computed for maternal demographics and past medical history, characteristics of the current pregnancy, and delivery. Categorical data are presented as $\mathrm{n}(\%)$ and continuous data as mean ( \pm standard deviation) or median (1st quartile, 3rd quartile), as appropriate. The chi-squared test was used to compare modes of delivery and proportions of discharges and preterm births between groups, and the Fisher exact test was used to compare the proportions of Caesarean section between groups. A two-sided $P<0.05$ was considered statistically significant.

\section{RESULTS}

From the 969 women who were entered into the CPN with $\mathrm{APH}$ as the primary indicator condition, 806 $(83.18 \%)$ were followed to delivery and included in our study.

Maternal characteristics and the causes of APH are shown in Table 2. While one third of women had a history of previous Caesarean section, 70 women $(16.68 \%)$ had a history of preterm delivery at less than 34 weeks and $32(6.71 \%)$ had had a previous stillbirth. Seventy-three women with a multiple pregnancy $(9.1 \%)$ were entered into the database. Placental abruption and placenta previa, respectively, were responsible for the bleeding in $256(31.8 \%)$ and $171(21.2 \%)$ women with APH. Less common causes included bleeding of cervical origin $(\mathrm{n}=53)$ and vasa previa $(\mathrm{n}=3)$. Forty-five women $(5.6 \%)$ had multiple causes of bleeding: 12 had a combination of 


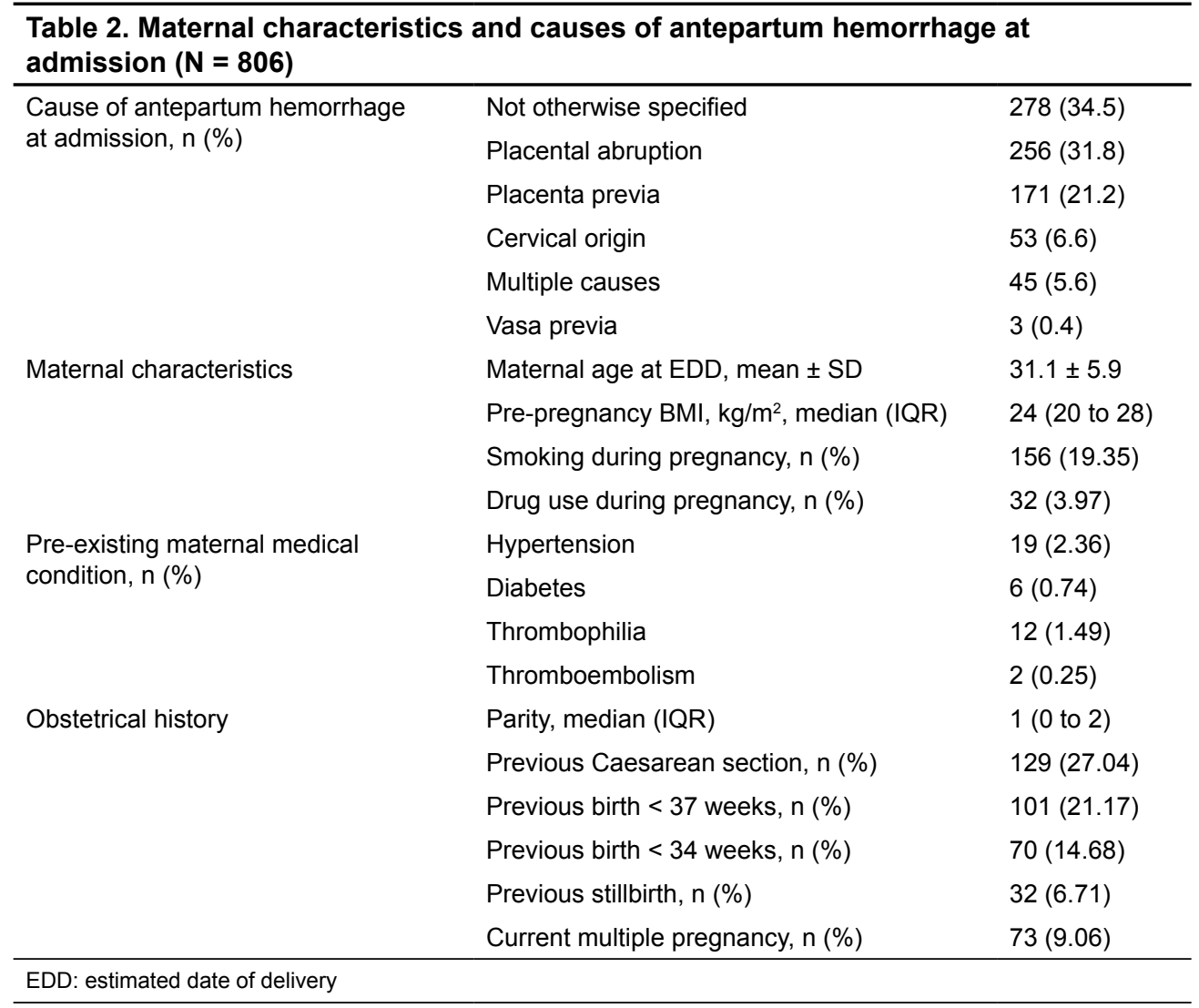

bleeding from abruption and cervical origin, eight had a combination of abruption and placenta previa, seven had a combination of placenta previa and cervical origin, one had a combination of placenta previa and vasa previa, and the remainder had bleeding NOS together with another cause. In the remainder of the cohort $(n=278)$, the cause of APH was NOS.

The admission characteristics of our study group are shown in Table 3. The median gestational age at enrolment into the CPN was 26 weeks (24 to 28 ) and was similar for all causes of APH. Median length of admission was four days (2 to 10) and ranged from three days in the NOS group to 44 days in the vasa previa group. Overall, 388 women $(48.1 \%)$ were discharged prior to delivery and this varied by cause of bleeding $(P<0.01)$ : women with bleeding of cervical origin were discharged prior to delivery most often, whereas women admitted with multiple causes of bleeding, vasa previa, or placental abruption were discharged before delivery only one third of the time.

\section{Timing of Delivery}

Overall, the mean gestational age at delivery was $31+3$ weeks $( \pm 5.68)$ and the median was $30+1$ weeks. The gestational age at delivery was earliest in the placental abruption group.
The median gestational age at delivery for the different causes of APH and the timing of delivery in relation to labour are shown in Table 4 . In 450 women $(55.8 \%)$, which included most of the NOS, abruption, and bleeding of cervical origin groups, delivery followed spontaneous labour. In contrast, 238 women $(29.5 \%)$, including all women with bleeding from vasa previa and one half of those admitted with placenta previa, delivered without having labour.

The high percentages of preterm birth, which varied according to the cause of bleeding $(P<0.05)$ are illustrated in Figure 1. With 167 deliveries (65.2\%) at less than 29 weeks' gestation, the placental abruption group had the highest proportion of very preterm deliveries. Overall, 605 women (75.1\%) delivered at less than 37 weeks, 497 (61.7\%) at less than 34 weeks, and $358(44.4 \%)$ at less than 29 weeks.

\section{Indication for Delivery}

The most common indications for induction of labour and Caesarean section are listed in Table 5. Ninety-eight women $(12.2 \%)$ had labour induced, including 30 from the placental abruption group, nine from the placenta previa group, eight from the cervical origin group, six with multiple causes of bleeding, and 45 with bleeding NOS. A term gestation was the most common indication for induction. This option was 


\begin{tabular}{lcccc}
\hline \multicolumn{4}{l}{ Table 3. Admission characteristics for women admitted with antepartum hemorrhage } \\
\hline $\begin{array}{l}\text { Type of } \\
\begin{array}{l}\text { antepartum } \\
\text { hemorrhage }\end{array}\end{array}$ & $\begin{array}{c}\text { Gestational } \\
\text { age at enrolment, } \\
\text { weeks, median } \\
\text { (IQR) }\end{array}$ & $\begin{array}{c}\text { Length } \\
\text { of admission } \\
\text { days, median } \\
\text { (IQR) }\end{array}$ & $\begin{array}{c}\text { Number of } \\
\text { admissions, } \\
\text { mean } \pm \text { SD }\end{array}$ & $\begin{array}{c}\text { Discharged before } \\
\text { delivery } \\
\mathrm{n}(\%)\end{array}$ \\
\hline NOS & $26(24$ to 28$)$ & $3(2$ to 7$)$ & $1.7 \pm 0.7$ & $160(57.6)$ \\
Abruption & $26(24$ to 27$)$ & $5(2$ to 9.25$)$ & $1.4 \pm 0.6$ & $79(30.9)$ \\
Placenta previa & $26(24$ to 27$)$ & $7(3$ to 27.5$)$ & $1.8 \pm 1.0$ & $98(57.3)$ \\
Cervical origin & $26(24$ to 28$)$ & $4(2$ to 9$)$ & $1.4 \pm 0.06$ & $34(64.2)$ \\
Multiple causes & $27(25$ to 28$)$ & $7(3$ to 20$)$ & $1.4 \pm 0.7$ & $16(35.6)$ \\
Vasa previa & $25(25$ to 26$)$ & $44(28$ to 53$)$ & $2 \pm 1.7$ & $1(33.3)$ \\
Overall & $26(24$ to 28$)$ & $4(2$ to 10$)$ & $1.6 \pm 0.8$ & $388(48.1)$ \\
\hline
\end{tabular}

\begin{tabular}{|c|c|c|c|c|c|}
\hline \multirow[b]{2}{*}{$\begin{array}{l}\text { Type of antepartum } \\
\text { hemorrhage }\end{array}$} & \multirow{2}{*}{$\begin{array}{l}\text { Gestational age } \\
\text { at delivery, weeks, } \\
\text { median (IQR) }\end{array}$} & \multicolumn{4}{|c|}{$\begin{array}{l}\text { Timing of delivery in relation to labour } \\
\qquad \mathrm{n}(\%)^{*}\end{array}$} \\
\hline & & No labour & $\begin{array}{l}\text { Spontaneous } \\
\text { labour }\end{array}$ & $\begin{array}{l}\text { Induction of } \\
\text { labour }\end{array}$ & $\begin{array}{l}\text { Augmented } \\
\text { labour }\end{array}$ \\
\hline Not otherwise specified & 30.4 (26.3 to 38.2$)$ & $39(14.03)$ & $185(66.55)$ & $45(16.19)$ & $26(9.35)$ \\
\hline Abruption & 27.6 (25.3 to 31.1) & $49(19.14)$ & $168(65.63)$ & $30(11.72)$ & $17(6.64)$ \\
\hline Placenta previa & $34.9(30.0$ to 37.0$)$ & $118(69.01)$ & $44(25.73)$ & $9(5.26)$ & $4(2.34)$ \\
\hline Cervical origin & $35.4(28.1$ to 38.4$)$ & $6(11.32)$ & $37(69.81)$ & $8(15.09)$ & $5(9.43)$ \\
\hline Multiple causes & 30.9 (27 to 35.9$)$ & $23(51.11)$ & $16(35.56)$ & $6(13.33)$ & $1(2.22)$ \\
\hline Vasa previa & 32.3 (32.2 to 34.5$)$ & $3(100)$ & $0(0)$ & $0(0)$ & $0(0)$ \\
\hline Overall & 30.1 (26.4 to 36.9$)$ & $238(29.53)$ & $450(55.83)$ & $98(12.16)$ & $53(6.58)$ \\
\hline
\end{tabular}

included in the database to encompass elective inductions of labour, when the benefits of delivery were felt to outweigh any benefit of continuing the pregnancy. Excessive vaginal bleeding or abruption was an indication for delivery in 11 and eight women respectively. In the abruption group, excessive vaginal bleeding was listed as a reason for delivery in six of 56 induced women $(20 \%)$. The eight inductions of labour for stillbirth were in the abruption $(n=4)$, NOS $(\mathrm{n}=2)$, placenta previa $(\mathrm{n}=1)$, and multiple causes of bleeding $(\mathrm{n}=1)$ groups.

The database listed 91 planned (non-urgent) Caesarean sections (placenta previa, $\mathrm{n}=49$; NOS, $\mathrm{n}=22$; abruption, $\mathrm{n}=9$; multiple causes, $n=6$; cervical origin, $n=4$; vasa previa, $n=1$ ) and 345 emergency Caesarean sections (abruption, $\mathrm{n}=120$; placenta previa, $n=99 ; \mathrm{NOS}, \mathrm{n}=83$; multiple causes, $\mathrm{n}=27$; cervical origin, $n=14$; vasa previa, $n=2$ ).

In 49 of 129 women (37.9\%) admitted with bleeding due to abruption and undergoing a Caesarean section, the indications included "abruption and/or bleeding" or "excessive vaginal bleeding." These were also the indications for Caesarean section in 11 of 33 women (33\%) admitted with multiple causes of bleeding and 31 of 148 women $(20.9 \%)$ in the placenta previa group. "Excessive vaginal bleeding" was most commonly an indication for Caesarean section in the placenta previa group. The proportion of women in each group who were delivered for the specific indications of placental abruption, excessive vaginal bleeding, non-reassuring fetal testing, placenta previa, or infection is shown in Table 6.

\section{Mode of Delivery}

In the entire cohort, as well as the placental abruption group, approximately half of the deliveries were vaginal and half were by Caesarean section (Figure 2). The proportion of assisted vaginal deliveries was similar in all groups $(P=0.81)$, but the proportion of spontaneous vaginal deliveries and Caesarean sections varied according to the cause of bleeding $(P<0.05)$. Overall, there were 330 spontaneous vaginal deliveries (40.9\%), 40 assisted vaginal deliveries (5\%), 345 emergency Caesarean sections (42.8\%), and 91 elective Caesarean sections (11.3\%). The 
Figure 1. Percentage of preterm deliveries at less than 29,34 , and 37 weeks for different causes of antepartum hemorrhage

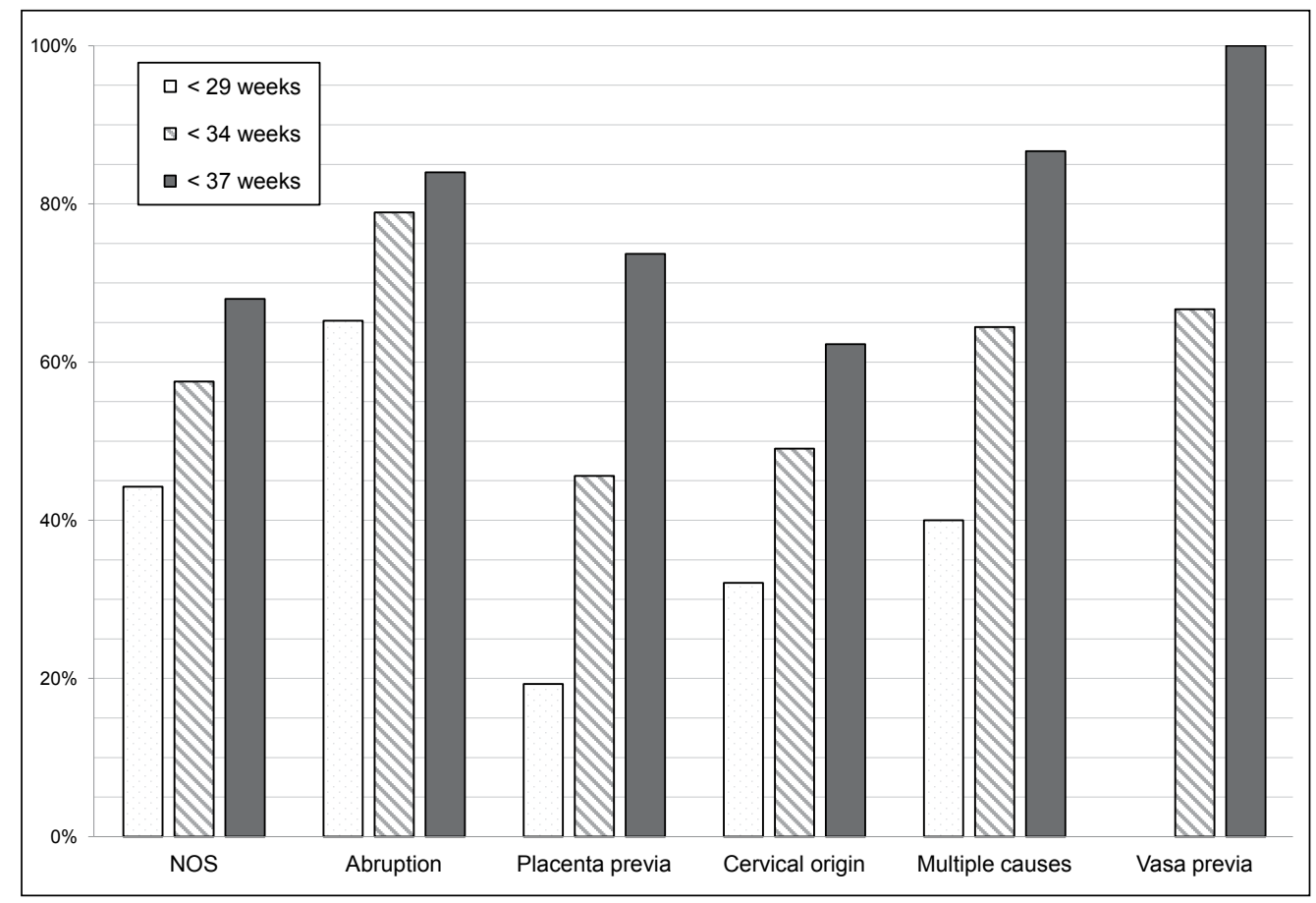

highest proportions of vaginal deliveries were in the groups with bleeding of cervical origin or NOS.

\section{DISCUSSION}

Within our cohort of Canadian women admitted with APH between $22+0$ and $28+6$ weeks' gestation to 13 participating tertiary care centres, the majority required hospitalization until delivery, went into labour spontaneously, and delivered preterm. A high proportion required a Caesarean section. The 23 vaginal deliveries in the placenta previa group are presumed to be cases of placental migration away from the cervix prior to delivery.

The baseline maternal characteristics of the study group included high rates of previous Caesarean section, previous preterm birth, and stillbirth, suggesting that this cohort is at risk of adverse pregnancy outcome. Previous preterm birth is the most important risk factor for recurrent preterm delivery. ${ }^{20}$ Previous Caesarean section is associated with an increased risk of placental abruption and placenta previa, and is possibly linked to stillbirth and preterm delivery. ${ }^{21}$ Preterm delivery, stillbirth, preeclampsia, and placental abruption have also been shown to be interrelated and may share a common etiology. ${ }^{22}$ Additionally, 73 women in the cohort had a multiple pregnancy, placing them in a group known to be at risk of preterm birth and operative delivery. ${ }^{20,23}$
We found that women admitted with bleeding due to placental abruption were least likely to be discharged prior to delivery, most likely among women with all types of bleeding to deliver at very early gestational ages, and most likely to require induction of labour or Caesarean section for bleeding. Placental abruption is the strongest known trigger of spontaneous preterm labour, increasing the risk four- to six-fold. ${ }^{24}$ In women in stable condition at early gestational ages, close surveillance in hospital is recommended because of the unpredictable nature of recurrent episodes of bleeding. ${ }^{24}$ In contrast, women admitted with bleeding of cervical origin were not at as high a risk for these outcomes; they had the latest median gestational age at delivery and delivered most often vaginally and after spontaneous labour.

A review of the existing APH literature shows similarities to and differences from this recent Canadian cohort of women. Nielson et al. described a similar group of 101 women with bleeding during the second trimester admitted to a single hospital between 1983 and $1989 .{ }^{16}$ Twenty-seven women had bleeding due to placenta previa, and 17 (63\%) of these women required Caesarean section. Eighteen of 26 live births $(69.2 \%)$ were preterm. Forty women were admitted with abruption and only 11 of them (27.5\%) delivered by Caesarean section. Thirty-two of 36 live births $(88.9 \%)$ were preterm, and there were five stillbirths. 
Twenty-three women were classified as having bleeding of unknown origin or other cause. Six of these women (26.1\%) delivered by Caesarean section, 11 of 22 live births $(50 \%)$ occurred preterm, and there were two stillbirths. The remaining 11 women had multiple causes of bleeding. As in our more recent cohort, the placental abruption group had the highest rate of preterm delivery and the shortest average interval from bleeding to delivery. Our higher rates of Caesarean section $(86.5 \%, 50.3 \%$, and $37.7 \%$ in the previa, abruption, and NOS groups, respectively) and preterm birth at less than 37 weeks $(73.7 \%, 84 \%$, and $68 \%$, respectively) may be explained by the fact that our cohort was larger, more recent, and derived from a diverse, possibly higher-risk, population from across the country. Management of women with APH, including a lower threshold for Caesarean section, more repeat Caesarean sections, or a lower threshold for earlier delivery due to increased neonatal survival, has likely changed with time. The prevalence of multiple gestations, which was only $2 \%$ in the study of Neilson et al, would also affect the incidence of preterm delivery and Caesarean section. ${ }^{16}$

In study that included 175093 women delivering at one hospital in Israel, 1580 pregnancies were complicated by vaginal bleeding in the second half of pregnancy. ${ }^{12}$ This group had a Caesarean section rate of $72.9 \%$, higher than our overall rate of $54 \%$. The spontaneous delivery rate was only $14.1 \%$ while $15.2 \%$ underwent induction of labour (compared with $40.9 \%$ spontaneous deliveries and $12.2 \%$ inductions in our cohort). ${ }^{12}$ Interestingly, the mean gestational age at delivery was 35 weeks, compared with the mean gestational age of $31+3$ weeks in our cohort. However, the bleeding in the Israeli cohort was entirely due to placental abruption $(63.5 \%)$ or placenta previa (36.5\%). ${ }^{12}$ In our CPN data, the Caesarean section rate was still lower at $64.8 \%$ (277 of 427 deliveries) when limited to those with placental abruption or placenta previa. We also observed that almost one half of the women admitted with abruption were delivered vaginally despite a median

\begin{tabular}{lc}
\hline \multicolumn{2}{l}{ Table 5. Most common indications for induction of } \\
labour and Caesarean section in women admitted \\
with antepartum hemorrhage* \\
\hline \\
\hline
\end{tabular}

${ }^{*}$ More than one indication for delivery per patient may be coded in the APH database.

\begin{tabular}{|c|c|c|c|c|c|}
\hline & NOS & Abruption & Placenta previa & Cervical origin & Multiple causes \\
\hline Excessive vaginal bleeding* & $5(4.8)$ & $10(7.8)$ & $24(16.2)$ & $0(0.0)$ & $3(9.1)$ \\
\hline Fetal distress ${ }^{*} \dagger$ & $14(13.3)$ & $20(15.5)$ & $8(5.4)$ & $4(22.2)$ & $8(24.2)$ \\
\hline
\end{tabular}

\section{${ }^{*} P<0.05$}

†Includes abnormal fetal heart rate or non reassuring fetal testing including biophysical profile or uterine artery Doppler 
Figure 2. Modes of delivery (\%) by causes of antepartum hemorrhage at admission

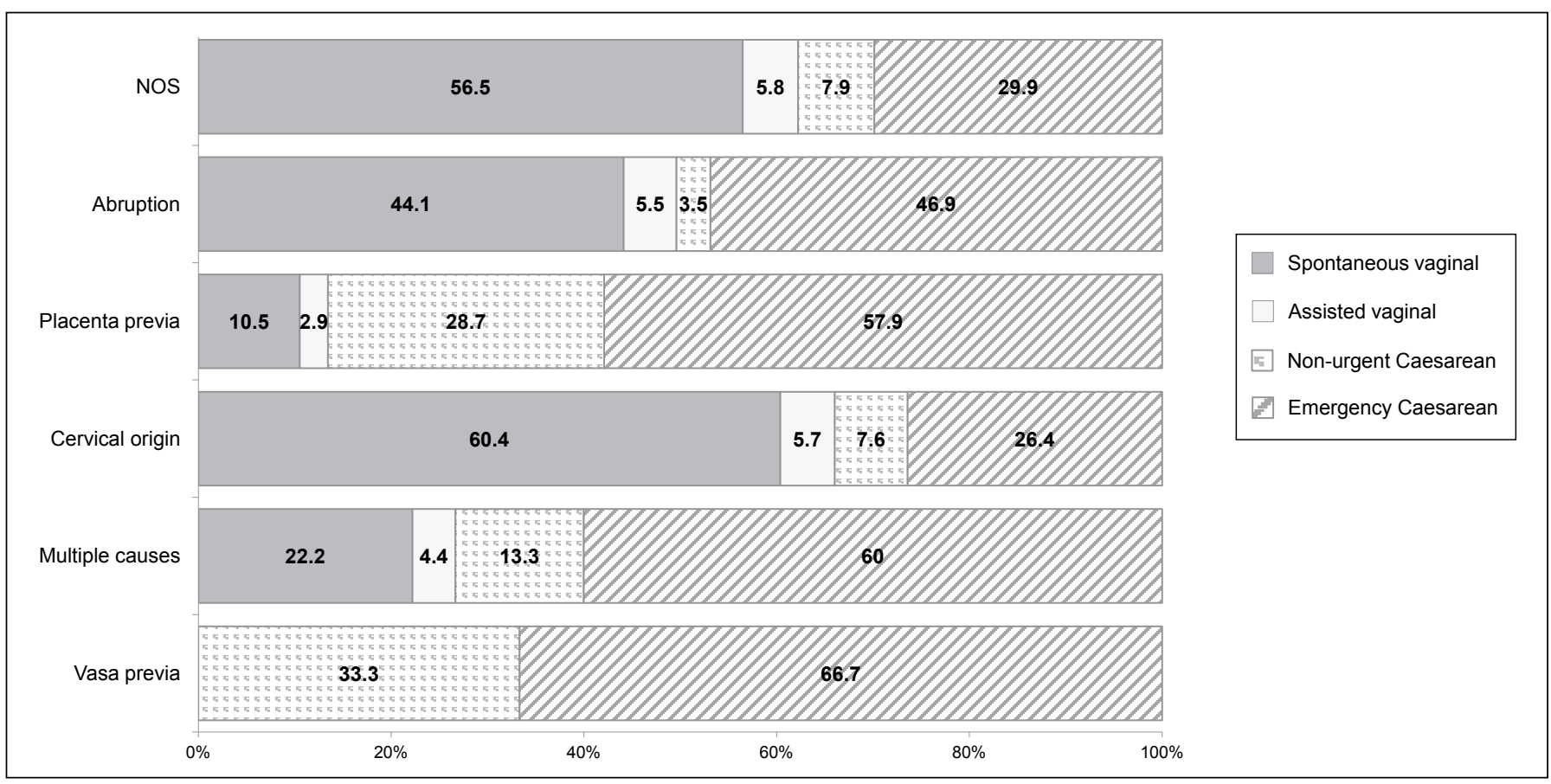

gestational age of only $27+4$ weeks. Most obstetricians currently agree that a trial of labour in cases of placental abruption is reasonable, but the safest mode of delivery in very preterm infants is controversial; some studies report increased perinatal mortality and other adverse outcomes with vaginal delivery. ${ }^{25-27}$ The $\mathrm{CPN}$ data will enable a future comparison of neonatal outcomes in groups delivered vaginally or by Caesarean section.

In contrast to these high Caesarean section rates, an earlier prospective study of 8718 women enrolled during an office visit and reporting on 206 cases of second trimester bleeding in women admitted to hospital (combined data for bleeding in the first or second trimester) found a much lower rate of $20.3 \% .{ }^{5}$ However, placenta previa and placental abruption were uncommon in this report (representing only 1.4\%), and the bleeding was not characterized in terms of timing or the need for admission, which precludes fair comparison. ${ }^{5}$

Bleeding of unknown origin can account for half the cases of APH. ${ }^{8}$ The CPN does not allow categorization as "unknown," although the NOS group would be expected to include a large proportion of women in this category. In a study that examined 67 cases of idiopathic vaginal bleeding in the second half of pregnancy, results similar to the group admitted with bleeding NOS in the CPN cohort were observed. The induction of labour rate was $17.9 \%$ and the Caesarean section rate was $35.8 \%$, compared with our rates of $16.2 \%$ and $37.8 \%$ respectively. ${ }^{10}$
Many studies report increased rates of preterm birth in women with vaginal bleeding during pregnancy (OR 1.3 to 3.17). ${ }^{2,5,9,13,28}$ In the CPN cohort, the rate of preterm birth at less than 37 weeks was $75 \%$, much higher than the $8 \%$ overall rate for Canadian births. ${ }^{29}$ This reflects the high risks associated with pregnancies requiring admission to tertiary care centres with APH in the second trimester. Yang et al. found that of 683 women enrolled in a prospective study who reported vaginal bleeding in the first or second trimester, half delivered at less than 36 weeks. ${ }^{13}$ Women experiencing bleeding had a $17.3 \%$ rate of prior preterm birth, similar to our $21 \%$ rate, but the authors did not report causes of bleeding or hospitalization rate, and they excluded multiple gestations. ${ }^{13}$ Bleeding was documented by telephone interview only. ${ }^{13}$ In another cohort of women in the United States, only 10 of 92 women with second trimester bleeding delivered between 34 and 36 weeks, and four delivered at less than 34 weeks. ${ }^{2}$ This study used an outpatient population base and excluded stillbirths at less than 28 weeks and multiple pregnancies. ${ }^{2}$ In another study in California of 128 women whose medical records documented a history of mid-trimester bleeding, rates of preterm birth between 24 and 37 weeks ranged from $30 \%$ in women with light bleeding to $53 \%$ in women with placenta previa and heavy bleeding. ${ }^{7}$

In comparison with these reports, our prospective CPN cohort includes only women with documented $\mathrm{APH}$ requiring admission to a tertiary care centre, includes pregnancies resulting in stillbirths, and includes a high proportion of 
women with previous preterm birth, placental abruption, and placenta previa, all factors that may account for the higher rates we observed of preterm birth. We have also analyzed the indications for delivery and timing in relation to labour, which were not reported in these previous studies.

The results of this cohort are representative of the current Canadian landscape. ${ }^{30}$ Our results are drawn from 13 of $23 \mathrm{CPN}$ tertiary care centres across the country that captured data from 2005 to 2011. Admission bias is minimized by Canada's universal health care and tertiary centre referral system. Furthermore, each perinatal unit has a trained data abstractor to identify and collect eligible cases. This and the re-abstraction of a proportion of cases limit misclassified or missing data. However, because the CPN includes only women admitted with APH between $22+0$ and $28+6$ weeks' gestation, our findings can be generalized only to this subset of women. The CPN does not capture women admitted with bleeding after $28+6$ weeks. A control group without bleeding or hospitalization is also not directly available for comparison, but our results are clinically helpful when counselling similar women on admission to hospital about the rates of hospitalization until delivery, preterm birth, preterm spontaneous labour, and emergency Caesarean section. Women may also find these descriptive data more useful than estimates of relative risk or risk ratios.

In addition to being limited to women admitted with APH between $22+0$ and $28+6$ weeks' gestation, it should be noted that this CPN cohort may give a more negative picture of their clinical course because a portion of women who were discharged subsequently gave birth at non-tertiary centres, conceivably with better outcomes and at later stages of gestation. These women are considered lost to follow-up in the CPN. In our cohort, the loss to follow-up approached $17 \%$. Also, as with any database lacking access to the individual charts and patients, items that are not otherwise specified or unknown can blunt results and lead to misrepresented conclusions, and the small numbers of rare conditions such as vasa previa may also preclude meaningful interpretation.

Many recommendations for delivery are based largely on expert opinion, and there is a need for evidence-based recommendations. Both the optimal mode of delivery in cases of preterm abruption and the timing of delivery in women with symptomatic placenta previa are disputed. ${ }^{31}$ Early delivery can increase the neonatal risks of prematurity, but delay may result in a catastrophic bleed. ${ }^{31}$ A commonly encountered clinical dilemma is the timing of induction of labour or delivery in high-risk, pre-term patients, and this is the group of women that the CPN attempts to capture. It is reported that emergency Caesarean section is associated with higher in-hospital maternal mortality and morbidity rates than elective Caesarean section or vaginal delivery. ${ }^{32}$ In our study, $62 \%$ of women were delivered at the time of spontaneous labour, and many required emergency Caesarean section. Does a planned earlier delivery reduce the risks to the woman and her fetus and outweigh the risks of prematurity? Using the additional maternal and neonatal outcome and intervention information in the CPN, our future analyses will aim to determine whether early elective delivery or a specific mode of delivery in subsets of women is beneficial. The obstetric and neonatal practices associated with the best outcomes can then be widely implemented throughout the country and audited through the CPN.

\section{CONCLUSION}

Within our cohort of Canadian women admitted with APH at between $22+0$ and $28+6$ weeks' gestation to one of 13 participating tertiary care centres, the majority required hospitalization until delivery, developed spontaneous labour, and delivered preterm. A high proportion required a Caesarean section. This study establishes current Canadian benchmarks for indications for delivery and for the timing and mode of delivery in women admitted between $22+0$ and $28+6$ weeks' gestation with antepartum hemorrhage. Our findings can be used by tertiary perinatal centres for counselling similar women and for comparing their centre's data against the national average. Our next analyses of the CPN cohort will focus on the maternal, perinatal, and neonatal outcomes of the APH cohort. Future studies using the $\mathrm{CPN}$ will focus on analyzing the antenatal, intrapartum, postpartum, and postnatal management strategies associated with the best outcomes in this high risk cohort in order to reduce maternal and neonatal morbidity and mortality in women admitted with APH.

\section{ACKNOWLEDGEMENTS}

Funding support was provided by the Canadian Institutes of Health Research and from the Ontario Ministry of Health and Long-term Care.

The authors would like to thank the CPN National and Site Coordinators.

\section{REFERENCES}

1. Axelsen SM, Henriksen TB, Hedegaard M, Secher NJ. Characteristics of vaginal bleeding during pregnancy. Eur J Obstet Gynecol Reprod Biol 1995;63:131-4.

2. Hossain R, Harris T, Lohsoonthorn V, Williams MA. Risk of preterm delivery in relation to vaginal bleeding in early pregnancy. Eur J Obstet Gynecol Reprod Biol 2007;135:158-63. 
3. Strobino B, Pantel-Silverman J. Gestational vaginal bleeding and pregnancy outcome. Am J Epidemiol 1989;129:806-15.

4. South J, Naldrett J. The effect of vaginal bleeding in early pregnancy on the infant born after the 28th week of pregnancy. J Obstet Gynaecol Br Commonw 1973;80:236-41.

5. Sipila P, Hartikainen-Sorri AL, Oja H, Von Wendt L. Perinatal outcome of pregnancies complicated by vaginal bleeding. Br J Obstet Gynaecol 1992;99:959-63.

6. Yang J, Savitz DA, Dole N, Hartmann KE, Herring AH, Olshan AF, et al. Predictors of vaginal bleeding during the first two trimesters of pregnancy. Paediatr Perinat Epidemiol 2005;19:276-83.

7. Towers CV, Burkhart AE. Pregnancy outcome after a primary antenatal hemorrhage between 16 and 24 weeks' gestation. Am J Obstet Gynecol 2008;198:684.e1-e5.

8. Norwitz ER, Park JS. Overview of the etiology and evaluation of vaginal bleeding in pregnant women. UpToDate 2011. Available at: http://www.uptodate.com/contents/overview-of-the-etiologyand-evaluation-of-vaginal-bleeding-in-pregnant-women. Accessed August 25, 2012.

9. Ananth CV, Savitz DA. Vaginal bleeding and adverse reproductive outcomes: a meta-analysis. Paediatr Perinat Epidemiol 1994;8:62-78.

10. Harlev A, Levy A, Zaulan Y, Koifman A, Mazor M, Wiznitzer A, et al. Idiopathic bleeding during the second half of pregnancy as a risk factor for adverse perinatal outcome. J Matern Fetal Neonatal Med 2008;21:331-5.

11. Signore CC, Sood AK, Richards DS. Second-trimester vaginal bleeding: correlation of ultrasonographic findings with perinatal outcome. Am J Obstet Gynecol 1998;178:336-40.

12. Koifman A, Levy A, Zaulan Y, Harlev A, Mazor M, Wiznitzer A, et al. The clinical significance of bleeding during the second trimester of pregnancy. Arch Gynecol Obstet 2008;278:47-51.

13. Yang J, Hartmann KE, Savitz DA, Herring AH, Dole N, Olshan AF, et al. Vaginal bleeding during pregnancy and preterm birth. Am J Epidemiol 2004;160:118-25.

14. Yang J, Savitz DA. The effect of vaginal bleeding during pregnancy on preterm and small-for-gestational-age births: US national maternal and infant health survey, 1988. Obstet Gynecol Surv 2001;56:449-50.

15. Lipitz S, Admon D, Menczer J, Ben-Baruch G, Oelsner G. Midtrimester bleeding - variables which affect the outcome of pregnancy. Gynecol Obstet Invest 1991;32:24-7.

16. Nielson EC, Varner MW, Scott JR. The outcome of pregnancies complicated by bleeding during the second trimester. Surg Gynecol Obstet 1991;173:371-4.

17. Canadian Perinatal Network.2010 [updated December 12, 2010]. Available at: http://www.cpn-rpc.org. Accessed October 15, 2011.
18. Ezzat H, Ross S, von Dadelszen P, Morris T, Liston R, Magee LA, et al. Ethics review as a component of institutional approval for a multicentre continuous quality improvement project: the investigator's perspective. BMC Health Serv Res 2010;10:223.

19. Magee LA, von Dadelszen P, Allen VM, Ansermino JM, Audibert F, Barrett J, et al. The Canadian Perinatal Network: a national network focused on threatened preterm birth at 22 to 28 weeks' gestation. J Obstet Gynaecol Can 2011;33:111-20.

20. Robinson J, Norwitz E. Risk factors for preterm labor and delivery. UptoDate 2012. Available at: http:/ /www.uptodate.com/contents/ risk-factors-for-preterm-labor-and-delivery. Accessed August 25, 2012.

21. Clark EA, Silver RM. Long-term maternal morbidity associated with repeat cesarean delivery. Am J Obstet Gynecol 2011;205(6 Suppl):S2-S10.

22. Lykke JA, Paidas MJ, Langhoff-Roos J. Recurring complications in second pregnancy. Obstet Gynecol 2009;113:1217-24.

23. Barrett J, Bocking A. Management of twin pregnancies (Part 1). The SOGC consensus statement. SOGC Clinical Practice Guideline, No. 91, July 2000. J Soc Obstet Gynaecol Can 2000;22:519-31.

24. Sheiner E, ed. Bleeding during pregnancy: a comprehensive guide. New York: Springer Science+Business Media; 2011.

25. Dani C, Poggi C, Bertini G, Pratesi S, Di Tommaso M, Scarselli G, et al. Method of delivery and intraventricular haemorrhage in extremely preterm infants. J Matern Fetal Neonatal Med 2010;23:1419-23.

26. Ment LR, Oh W, Ehrenkranz RA, Philip AG, Duncan CC, Makuch RW. Antenatal steroids, delivery mode, and intraventricular hemorrhage in preterm infants. Am J Obstet Gynecol 1995;172:795-800.

27. Hogberg U, Holmgren PA. Infant mortality of very preterm infants by mode of delivery, institutional policies and maternal diagnosis. Acta Obstet Gynecol Scand 2007;86:693-700.

28. Magann EF, Cummings JE, Niederhauser A, Rodriguez-Thompson D, McCormack R, Chauhan SP. Antepartum bleeding of unknown origin in the second half of pregnancy: a review. Obstet Gynecol Surv 2005;23:741-5.

29. Statistics Canada. Births (2008) catalogue no. 84F0210XWE. Ottawa: Statistics Canada; 2011. Available at: http://www.statcan.gc.ca. Accessed November 30, 2011.

30. Massey KA, Magee LA, Dale S, Claydon J, Morris TJ, von Dadelszen P, et al. A current landscape of provincial perinatal data collection in Canada. J Obstet Gynaecol Can 2009;31:236-46.

31. Spong CY, Mercer BM, D'alton M, Kilpatrick S, Blackwell S, Saade G. Timing of indicated late-preterm and early-term birth. Obstet Gynecol 2011;118(2 Pt 1):323-33.

32. Liu S, Liston RM, Joseph KS, Heaman M, Sauve R, Kramer MS, et al. Maternal mortality and severe morbidity associated with low-risk planned cesarean delivery versus planned vaginal delivery at term. CMAJ 2007;176:455-60. 